\title{
Melvin's Mind Style: A Corpus Stylistic Analysis of As Good as It Gets
}

\author{
Eman Adil Jaafar \\ Department of English, College of Education for Women, \\ University of Baghdad \\ eman_jafer@coeduw.uobaghdad.edu.iq
}

\begin{abstract}
This study primarily attempts at examining the mind style of the leading character in the 1997 film As Good as It Gets performed by Jack Nicholson as Melvin Udall, a novelist who is characterized as a misanthrope, and suffers from obsessive-compulsive disorder (OCD). The main aim of this paper is to examine the mind-modeling of the character's mind for his unique odd mind style. This can be achieved by applying both qualitative and quantitative methodologies. The adopted methodology is based basically on McIntyre and Archer (2010) and McIntyre (2015); it shares some of the perspectives that require using Wmatrix (Rayson, 2008) to perform the quantitative analysis in order to validate the qualitative data. However, this study, does not aim to measure consistency. This paper aims at: first, verifying the usefulness of one of the corpus tools in understanding the deviant mind of the character. Second, analyzing key semantic domains of the speech of the main character as well as the keywords used by him. In addition to that, the researcher tries to benefit from cognitive linguistics schema theory in understanding the odd mind style of the character.
\end{abstract}

Keywords: corpus stylistics, cognitive poetics, film discourse, key semantic domains, mind style, schema theory

Published online: 31 October 2019

To cite this article: Jaafar, E. A. (2019). Melvin's Mind Style: A Corpus Stylistic Analysis of As Good as It Gets. International Journal of Language, Literacy and Translation 2(2), 29-41. https://doi.org/10.36777/ijollt2019.2.2.025

To link to this article: https://doi.org/10.36777/ijollt2019.2.2.025 


\section{INTRODUCTION}

This paper aims at showing how corpus and cognitive stylistics are connected in a way or another. To achieve this goal, it is important to define these contemporary concepts. Firstly, cognitive stylistics draws on cognitive approaches to study literary text. In other words, stylisticians here, borrow the required tools to study 'mental faculties' in understanding perception and other 'cognitive mechanisms' (Culpeper, 2001, Gibbons \& Whiteley, 2018).

Secondly, corpus stylistics refers to the corpus approach to the study of stylistic matters. It involves applying computer tools to answer stylistic concerns in a particular text/s. This requires applying qualitative and quantitative methodologies (Mahlberg, 2014; Biber, 2011; Gibbons \& Whiteley, 2018).

This study is conducted to achieve what McIntyre (2015) highly recommends and encourages to integrate corpus stylistics and cognitive stylistics. I share with him the main idea that both areas of stylistics cannot be developed separately and they complement one another. McIntyre (2015) argues:

I argue that what is needed is integrated corpus stylistics; that is, an approach to corpus-based stylistic analysis that takes account of all appropriate analytical frameworks (including but not limited to those from cognitive stylistics) and is not restricted by only utilizing the tools and techniques of corpus linguistics. Indeed, for corpus stylistics to distinguish itself from corpus linguistics generally, it needs to incorporate theories, models, and methods of qualitative stylistic analysis to augment computational techniques (p. 60).

In addition, he argues that all the earlier definitions of corpus stylistics are unsatisfactory. He does not accept the fact that what distinguishes corpus stylistics from corpus linguistics is the subject matter of the study. Putting it differently, it is not enough to distinguish corpus stylistics from its major focus on literature as opposed to non- literary language.

On that basis, McIntyre (2015) redefines corpus stylistics "as the application of theories, models, and frameworks from stylistics in corpus analysis"(p. 61).

The integration of corpus stylistics with cognitive stylistics is highly encouraged. McIntyre (2015, p. 63) ascertains that this fruitful disciplinary marriage can give further insightful results and can provide stylisticians with the unrevealed perspectives of the two disciplines.

Corpus stylistics pays heed to patterns of large texts while cognitive stylistics focuses on the relationship between readers and texts while reading. As well as, with the mechanisms of reading and how certain information is processed in the mind and consequently understood and digested.

The main focus of this paper is to study Melvin's mind style. It is assumed that his way of thinking is unique. Thus, applying the tools of corpus and cognitive stylistics helps to gain a better perspective on the study of mind style.

The study hopes to gain some clues from the script to understand the bizarre mind style of the leading character of the film As Good as It Gets. Melvin suffers from OCD, his impoliteness and difficulty to cope with the people around him, makes him a suitable case study for examining mind style. 


\section{MIND STYLE}

Originally, the term mind style is coined by Roger Fowler (1977). The famous quotation that defines the concept is stated as follows:

- 'Cumulatively, consistent structural options, agreeing in cutting the presented world to one pattern or another, give rise to an impression of a world-view, what I shall call a "mind-style" (Fowler, 1977, p. 76).

In his later work, Fowler (1996) refined and explained the notion of mind style "The worldview of an author, or a narrator, or a character, constituted by the ideational structure of the text" (Fowler, 1996, p. 21). On that basis, many studies have benefited from Fowler's establishing ideas about mind style will be shown next in this paper.

These studies aim to comprehend uniquely bizarre minds. Researchers put their efforts to tackle this issue by applying corpus stylistics solely or combined with other methodologies to gain insightful interpretations. Another study by Palmer (2004, p. 84) concerned with understanding the minds of characters bring our attention to the fact "The presentation of the mind in narrative fiction is a dynamic process, a negotiated relationship between the narrator, the character, and the reader in which a set of formal conventions is given meaning by the reader' (see also Palmer, 2002).

\section{RELEVANT WORK}

Recent stylistic studies show an inclination to combine and integrate corpus and cognitive studies in terms of text analysis. For instance, Stockwell and Mahlberg (2015, p. 129) suggest "an innovative approach to literary discourse". Their work aims to analyze Dickens' David Copperfield by applying both the tools of corpus linguistics and cognitive poetics (cognitive stylistics). Their approach seeks to study mind-modeling in creating the characters of the text. In addition, the work attempts to examine the modeling of the writer's mind with the modeling of the characters' mind. This can be achieved with the help of corpus linguistics which helps to "identify textural patterns that function as cues triggering character information"(p. 1).

Another study that emphasizes the importance of integrating both cognitive and corpus stylistics by McIntyre (2015). His article poses crucial points. He ascertains that the importance of integrating corpus stylistics with other stylistic methodologies e.g. cognitive stylistics. This is essential in terms of distinguishing between corpus stylistics and corpus linguistics for the difference remains unrecognizable.

Haddon's novel The Curious Incident receives the attention of many stylisticians and linguists to study idiosyncratic features of a character's mind style. In his (2015) work, McIntyre tries to analyze extracts from The Curious Incident of the Dog in The Night-Time and Deadwood in the first novel, the case study is the teenager Christopher who is diagnosed with Asperger's Syndrome. His basic difficulties are understating metaphors as well as his incapability to generate reported speech. The novels were annotated and compared to a reference corpus of contemporary fiction. McIntyre followed the methodology of Leech and Short (1981) which is later developed by Short and Semino (2004). He concluded that the use of direct speech is much 
more frequent in comparison to other novels. This validates his initial hypothesis about the overuse of direct speech (P. 64).

Similarly, the work of McIntyre and Archer (2010) was basically about examining Mrs. Shepherd's mind style in The Lady in The Van. They want to continue what McIntyre (2005) originally investigated about this eccentric character. However, they sought to examine the consistency of mind style by applying computational semantic analysis, which can be executed by using Wmatrix (Rayson, 2008). They aim to investigate to what extent quantitative analysis is useful in this regard (p. 167).

In her work, Semino (2008) applies both cognitive metaphor theory and blending theory to examine the mind style of the main character of Fowles's novel The Collector. The former theory helps to find some of the salient features or aspects of the leading character, his conceptual structure and cognitive habits. Blending theory helps to examine and understand his main acts under serious situations (p.276). In her study of mind style, Montoro (2011) proposes a way of studying the characters' unconventional mind style in the film Enduring Love (2004) based on the novel (1997) by Ian MacEwan with the same title. In her study, she tries to bring attention to certain cinematic techniques that are employed to project the characters' unconventional mind style. She discusses there are "cinematic mind style indicators" like non-verbal and gestural means of communication and she ascertains that these indicators should be studied further.

Moreover, Montoro (2011) explains that gestures can communicate information just like written language. For this reason, it should not be neglected. Jed Parry, the character in the previously mentioned film has an unusual, unconventional mind style. He keeps misunderstanding Joe Rose's gesture (the curtains gesture), another bodily language as indicators of love while the fact shows the opposite. Parry's mental eccentricity and his psychological state, his unique way of thinking makes him focus mistakenly on such details and consequently misinterpret the facts.

On more studies presented by Leech and Short (1981 \& 2007) and in their significant study of mind style illustrate that "the fictional world is what is apprehended, whereas our present concern is with how that world is apprehended, or conceptualized"(p.187). In their book Style and Fiction, they attempt at analyzing Benjy's deviant mind style in the Sound and the Fury by Faulkner focusing basically on lexical and syntactic levels. They observe that Benjy uses mainly monosyllabic words near to 80 percent of his vocabulary. Other words are di-syllabic. Moreover, the simplicity of syntax is quite obvious. Benjy who suffers from autism has great difficulty in describing a game of golf, which leads to difficulty for readers to understand what exactly this part of the novel means. For more details about the characterization of Faulkner's character see Bockting (1994).

In an attempt to benefit from corpus tools, especially WordSmith, Semino (2007, p. 13) identifies five keywords (I, and, because, then, said) and tries to find indications about Chris' eccentric mind style. After that, she benefits from concordance tools to search for speech act verbs. She concludes that Benjy's underlexicalisation is quite distinctive from the use verbs such as (say and tell).

The previously mentioned and highlighted studies focus on mind style, though, the stylisticians have applied different tools. Some have focused on syntactic issues; others have integrated cognitive approaches to achieve desired interpretations. In this research, I will combine corpus stylistics with cognitive theory, hopefully, to gain some insightful linguistic clues. 


\section{KEY RESEARCH QUESTIONS}

The following research questions guide the present study:

RQ1: How can Wmatrix help in revealing certain aspects about mind style?

RQ2: To what extent cognitive approach helps to understand Mr. Udall's odd mindset and the process of characterizations?

RQ3: In what way key semantic domains and keywords help in revealing aspects related to mind style of the character?

\section{METHODOLOGY}

In this study, both quantitative and quantitative methods are applied as mentioned earlier. Employing corpus stylistic means using the computer tool Wmatrix to conduct part of the process of the analysis. Examining the patterns and keywords and other important features related to the text by means of quantitative methods. The other part of the analysis is a qualitative one. The researcher argues that the quantitative analysis would be insignificant without the help of manual analysis. Using one of the theories of cognitive stylistics, in particular, schema theory to examine how readers interact with the text. This part of the study is particularly being influenced by Semino's (1995) work, which shows how schema is important to understand the world of the characters in texts.

In fact, the researcher tries to experiment with what has already been suggested by McIntyre and Archer (2010) and McIntyre (2015) as well as Stockwell and Mahlberg (2015). These studies ascertain the importance of integrating corpus and cognitive studies. This study aims at examining the significance of keyness as claimed by McIntyre and Archer (2010) in revealing mind styles. This study is eclectic in terms of adopting different strategies and frameworks from other fields of study. This is actually what is encouraged in McIntyre's (2015) work. Focusing on the basic advantage of stylistics, which helps to borrow tools from different disciplines.

\section{DISCUSSION AND RESULTS}

\section{THE DEVIANT MIND STYLE OF MELVIN IN AS GOOD AS IT GETS}

This section of the study deals with the main concept of mind style. It further aims to point out the odd characteristics of the character of the study. Starting with crucial issues addressed by Stockwell (2015) who illustrates fundamental points related to mind-modeling of the characters in the text while reading. Readers employ their sets of thoughts, notions and feelings. As readers, we try to understand the writer's mindset. Stockwell believes that,

"we imagine other people to have a consciousness like our own, and we fill in further details about their lives, thoughts, and perspectives. This cognitive poetic account of characterization draws on the notions of 'theory of mind' and simulation from cognitive psychology"(p. 240).

Then Stockwell (2015) illustrates that: 
"Mind-modelling is an everyday process that we use to keep track of our different relationships with every person in our lives. Literary mind-modeling is no different. Of course, readers' mind-model not only fictional characters but also the imagined authors of those literary works"(p. 225).

Based on these facts, the main focus of this study is the characterization of Melvin, who is skillfully created by James L. Brooks and Mark Andrus.

Melvin Udall is a writer of romantic fiction. His personality in real life shows quite a different attitude to romanticism. He is rude, misanthropic, unneighbourly person who suffers from obsessive-compulsive disorder (OCD). This disorder is a mental one. People with OCD incline to have recurrent thoughts of repeating the same actions and things. This can affect their personal relationships in a negative way (Obsessive-compulsive disorder, 2016).

Readers of the film script and anyone who watches the movie can easily notice Melvin's freakish behavior. Interestingly, he is a writer of romantic stories, in real life, he acts as a queer person. The characters around him feel uncomfortable while dealing and communicating with such an odd personality. It is, thus, this eccentricity that made Melvin a perfect case for studying mind style.

Qualitatively speaking, there are certain qualities and peculiarities that enable analysts to observe the oddness of his character. These include his extreme rudeness while speaking and dealing with the surrounding characters. His insensible behavior towards others and his selfishness. He cannot accept changes in his daily routine. When Carole (the waitress) is absent from her work at the café, he could not accept the fact that she has responsibilities as a human being. Another example is when he finds his table occupied by others, he tries his best to disturb them in order to get it back so that he can sit and have his breakfast at the same place as he always does. His behavior at the beginning of the story with the dog and how he throws it in the trash shows his extreme insensitivity. Finally, his way of walking. He avoids stepping over the lines of the cracks in the streets. All these features give a clear idea about his mind style.

Mr. Udall's deviant mind style is illustrated by his actions throughout the two hours and eighteen minutes of the film As Good as it Gets. He is obsessed with cleanliness as this is an attribute of those who are diagnosed with OCD. He detests the little dog of his neighbour Simon, as he believes it is a walking germ. He wears gloves when he tries to get rid of the dog and throws it in the garbage chute. After this, he cleans his hands with neutrogena soap bar with almost boiling water and discards it. He repeats the same action with another new soap and throws it away. Melvin hates to be touched by others. When he walks, he keeps repeating 'Don't touch'. However, this is not the case with Carol, the waitress, for example:

"Melvin intentionally moves a step in her path, with stealth, so that she must touch him again to get him out of the way".

Another example of his deviant mind style, he takes with him a plastic picnic ware when he goes to the café to have his meal. His inability to change the routine situations and inability to cope with new happenings also show a deviant mind of this unconventional character. He does not accept people to sit at the table that he usually sits in at the café. This fact is clear on a couple who were sitting and he did his best to let them leave the place. He called them 'jews' and simply said:

"How much more you got to eat? 
Your appetite isn't as big as your noses, is it?

His attitude strikes our conventional ideas about dealing with others. Melvin's unconventional actions arouses curiosity which leads to examine his mindset.

To illustrate further about this case study, a corpus search of key semantic domains is conducted to gain a quantitative overview of the text. Figure 1 below shows the basic domains in the text:

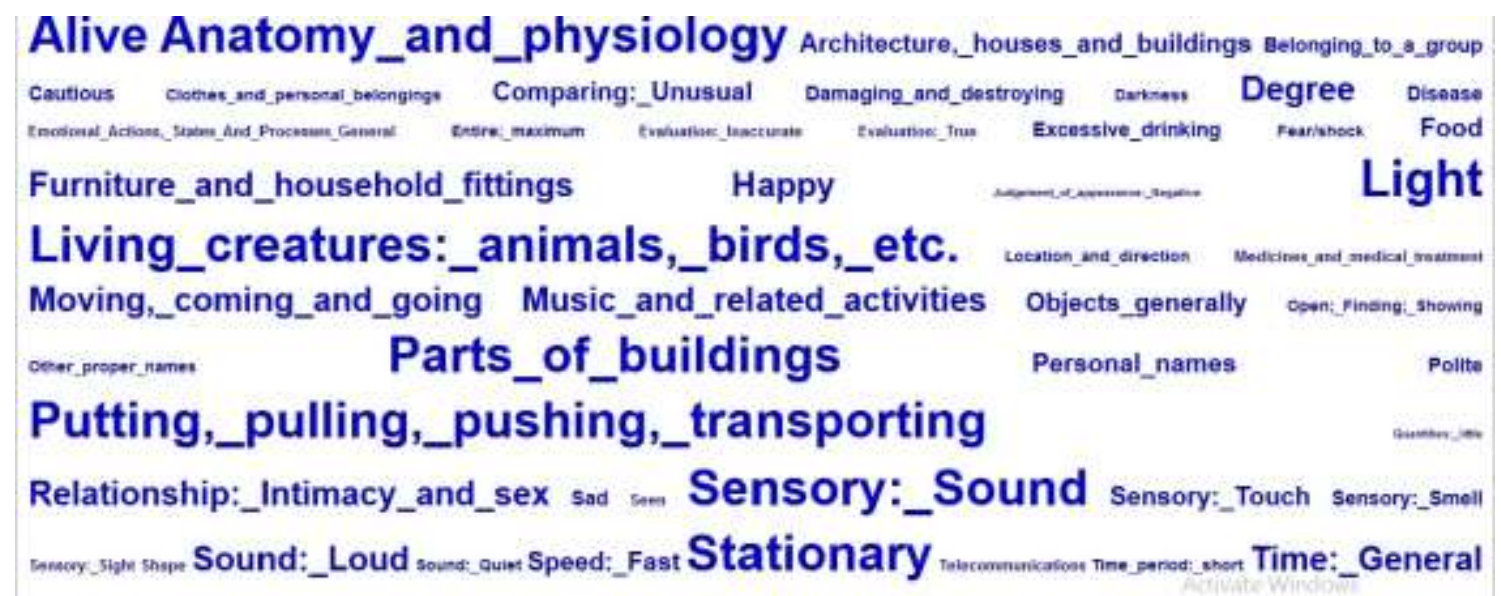

Figure 1: Screenshot Retrieval of Key Semantic Domains using Wmatrix

Key Semantic domains (see, Jaafar, 2017, 2019; Mahlberg \& McIntyre, 2011) give a clear picture of the character's mindset. In other words, locating words to their semantic domains helps to focus on what is dominant in terms of thematic as well as the lexical importance of the text.

In reference to Figure (1) the semantic domain Alive, anatomy and physiology indicates the significance of body language or gestures used in the text. Some of these include; (hands, pissed, noses, chest, heads, fingers, face, palm, crotch, erection etc). Contextual examples like:

His eyes focused on the terrain (to avoid stepping on cracks) shows the unusual aspect of Melvin's mind style, who has a problem of walking normally in the street.

The other domain living creatures, animals, birds, etc. illustrates the repetition of the word 'dog' refering to 'Verdall' the dog with which Melvin shows some communication problems. Melvin used to treat the dog as a filthy creature. Then this relationship between human/animal changes significantly as certain situations altered.

After examining this domain, it is obvious that other names of animals are exploited in an impolite way, as a means of attacking people who communicate with Melvin directly. Basically, his rude behavior towards others and his carelessness about hurting people's feelings without regret is the main interest in the study. Examples which demonstrate his odd mind style include: "Hey, elephant girl, call her" when he noticed that Carol is not in the café, instead of asking Carol's colleague in a polite way, he directly attacks her with the word "elephant".

"You dog-eared monkey" while talking to Verdall the dog. 
In order to start the quantitative analysis, the text is converted into a plain text format. The focus is on the main character's speech and stage directions. The second step is comparing the speech to BNC sampler spoken since the script is written to be acted and the words are meant to be spoken. The stage directions by the screenwriters are kept for the sake of the analysis. I would argue that these directions are crucial. These can give further insights and richness to the analysis.

Keyword analysis by Wmatrix has certain points to be taken into consideration. Rayson (2008) emphasized that "You should just look at items with a '+' code since this shows overuse in your text as compared to the standard English corpora. To be statistically significant you should look at items with a log-likelihood value (LL) over about 7, since 6.63 is the cut-off for $99 \%$ confidence of significance"(Wmatrix, web).

Figure 1 illustrates a keyword cloud which shows keyness of words. The bold words have much significance and importance as Rayson (2008) mentions. Keyword clouds are arranged alphabetically.

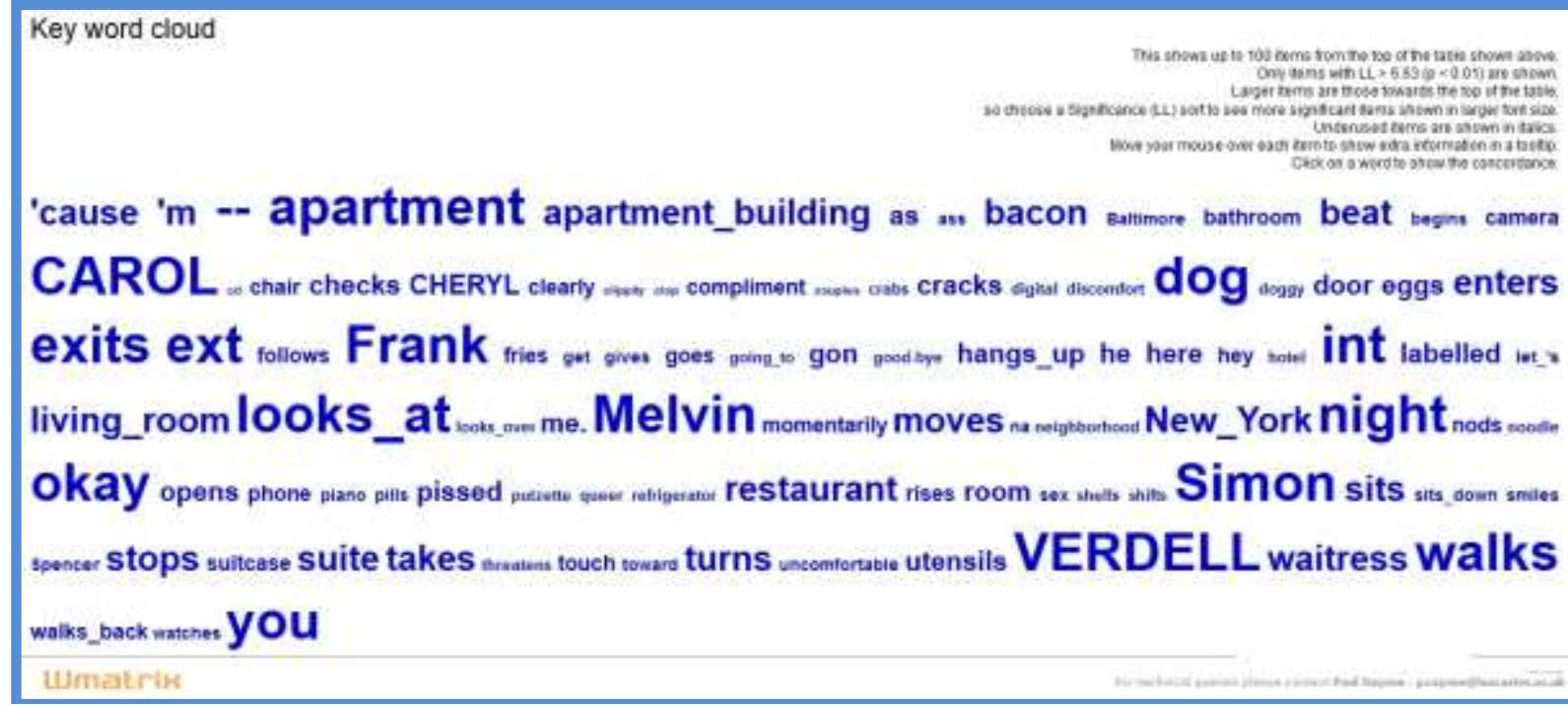

Figure 2. Screenshot of Wmatrix's keywords clouds of Melvin's speech in Comparison with BNC Spoken

It is worth mentioning at this point, the total number of words in Mr. Udall's speech file is 7,106 words. This is converted to plain text and uploaded to Wmatrix tool. The speech is extracted from the original script file of the film, which contains 21,163 tokens in total. In order to conduct an analysis at the word level, a suitable corpus reference must be selected.

There has been an attempt to use a simple filter before retrieving the keyword list in order to exclude words with high frequency, such as function words as Rayson (2008) recommends. The filter facility is available to perform this action. Function words are not of a particular interest here in the current study.

Table 1

Keywords of Melvin's speech in Comparison with BNC Spoken

\begin{tabular}{|c|c|c|}
\hline Rank & Word & LL( critical value $=15.13)$ \\
\hline $\mathbf{1 .}$ & Melvin & 14.43 \\
\hline $\mathbf{2 .}$ & Carol & 11.72 \\
\hline $\mathbf{3 .}$ & Simon & 10.9 \\
\hline
\end{tabular}




\begin{tabular}{|c|c|c|}
\hline $\mathbf{4 .}$ & Verdell & 10.30 \\
\hline $\mathbf{5 .}$ & Apartment & 8.93 \\
\hline $\mathbf{6 .}$ & Exits & 8.50 \\
\hline $\mathbf{7 .}$ & Frank & 8.24 \\
\hline $\mathbf{8 .}$ & Apartment-building & 8.47 \\
\hline $\mathbf{9 .}$ & waitress & 7.92 \\
\hline
\end{tabular}

Table 1 shows the top ten keywords in Melvin's speech. This shows statistical importance with a log-likelihood value over 7. It is clear from the table proper names have the greatest significance in Melvin's life. Carol then the dog Verdell have a special place in Melvin's world. Then we can notice the other two, Simon and Frank. The words apartment and apartment-building have also a recognizable prominence that gives an idea about Melvin's life. He spends considerable time in his apartment due to the nature of his work as a writer. Not only this, he is a socially isolated person who has communication difficulties.

Finally, returning to RQ1 and RQ3, the statistical results in Figure 1 as well as the data clarified in Figure 2 shows that corpus stylistics and in particular the study of key semantic domains and keywords are of a tremendous importance to this particular study.

\section{COGNITIVE POETICS AND MIND STYLE}

In order to seek an answer to RQ2, this section will further enhance our understanding of schema theory and how it supports the comprehension of Melvin's mindset. Stockwell( 2009) stresses the idea of how readers view the world view of the characters by employing 'the cognitive mechanics that readers must engage in when experiencing fictional literary works and the beings which inhabit them'( p. 106).

In this article, there is an attempt to approach mind style by means of an interdisciplinary study. Trying to benefit from cognitive linguistic theories, schema theory enables readers, sensors, observers or audience to connect what they actually see or read with their background knowledge. Schema theory is one of the pillars of cognitive stylistics. Originally created by the psychologist, Bartlett (1932) which based on the idea of how our minds process information during the process of reading a particular text. Cook's (1990) work, explores different terms related to schema theory. These include:

- Schema adding( add new information to the existing one);

- Schema refreshing( refreshing our existing knowledge about certain situations;

- Schema reinforcement and,

- Schema disrupting (unfamiliar information, deviating ideas).

Semino (2002, p. 98) points out an important fact related to the study of mind style, "if mind style is to do with the linguistic construction of a particular conceptualization of a textual world, it is best approached by combining the analysis of linguistic patterns with theories of cognition". The activation of schema is crucial to arrive suitable conclusions.

Relevant to this, Semino (1995, p. 5) describes schema as "mental representations". The readers' schema can be challenged, refreshed or disrupt our existing background knowledge about a particular situation. 
Hoover (2016) suggests in his chapter about mind style, what readers perceive as strange is either in the world or the character's mind. He continues to suggest that an abnormal "fictional world" can cause impairment in the characters' mind style. Moreover, he argues it is not necessarily true with all mind impairments (p. 327).

Schema helps to comprehend the nature of narrative, how schema shows inference can be made to link these events, providing extra information and interpretation of what is stated (Emmott, Alexander, \& Marszalek, 2014, p. 270).

Schema theory involves studying mind style which involves examining the style of thought of a character who perceives the world differently from adults like insane people and children. The term "mind style" refers to the deviant thinking style rather than thinking style in general. The use of schema theory to identify "literariness" which Cook (1990) links to what he calls "discourse deviation", that means a literary discourse is schema refreshing where the readers update, change or transform the existing schema, while non-literary discourse is simply schema reinforcing. Furthermore, schemata are related to knowledge which readers have in common, but social and cultural groups may have different kinds of knowledge. Socio-cultural schemas depend on factors like gender, age, race, class and other different areas in socio-cultural studies (Emmott, Alexander, \& Marszalek, 2014, p. 271).

Emmott, Alexander, and Marszalek (2014) suggest that reading is not a matter of processing facts but it is a matter of feeling a real sense of the world of the text so we need a sensory schema to explain our awareness of what is involved by basic perception such as vision, hearing, smell, touch, and taste (Emmott, Alexander, \& Marszalek, 2014, pp. 272-273).

It is worth noting that one of the limitations of schema theory is basically related to cultural differences or background experiences. What might be familiar in one culture might be odd in a different one. Also, there can be differences from one person to another. However, this limitation does not affect cognitive reading and the perception of Melvin's mind style. Impoliteness is something intolerable universally. His actions, words, rudeness are bizarre. That's what makes Melvin a suitable case for this study.

Finally, the oddity of Melvin's style is marked by striking our own comprehension of certain behavior with the people around him. Readers have a particular schema conception about how to get along with individuals.

However, there is a hint that love acts as a remedy that affects his illness and his odd mind style. Carol complains that she wants a normal boyfriend. After some time, he admits to Carol when she asks him to pay her a compliment. In fact, she doubts his capability of being a nice person who can pay compliments. Surprisingly, his indications that "he begins to take his medication pills to become a better person". This shows his awareness of the problems that he has. After that, she comments that this is the best compliment in her entire life. Finally, schema theory is one of the cognitive stylistics theories which guides the analysis to approach Melvin's mind style.

\section{CONCLUSIONS}

In this article, there has been an attempt to analyze the speech of the main character, Melvin in a film script of As Good as It Gets. The study aimed to show how mind style is tackled by applying both corpus and cognitive stylistics in understanding the character's mindset. He suffers from OCD and has serious issues in dealing socially with his surrounding environment. His 
inability to have good relationships due to his inclination to be alone as well as to his rude behavior. The use of a computational tool helps to identify semantic domains in the character's speech as well as the keywords. In addition to that, there is an attempt to achieve an interdisciplinary study by integrating and benefitting from both tools of corpus linguistics and cognitive poetics. Schema theory here in this study supports the quantitative analysis presented by Wmatrix.

Key semantic domains revealed certain aspects of Melvin's issue with OCD. Identifying body parts, for instance, hands, faces, are associated with repetitive actions, a common attribute of this disorder. Similarly, keywords retrieval results showed how Melvin's world is limited to certain person, which again confirms his social alienation (another attribute of OCD).

The synergy of the two fields of stylistics in this research is significant. Schema theory is helpful in terms of identifying the peculiarities of Melvin's mindset. Our background knowledge is disrupted by his verbal and nonverbal communicative actions with others.

Overall, examining idiosyncratic features of characters' mind holds the interest of many stylisticians. Few studies have been devoted to developing this particular study, employing linguistic tools individually or collectively. Some of the scholars apply theories of cognitive poetics (for example, text world theory, metaphor, schema) to study mind style of different characters who are characterized by impairments in their way of thinking and processing the world. Other stylisticians attempt to conduct analyses by means of interdisciplinary studies. In other words, integrating corpus and cognitive studies. Their attempts were fruitful yet more work needs to be given considerable attention with regard to examining mind style with the help of corpus tools. That can achieve to some extent what distinguishes corpus stylistics from corpus linguistics as McIntyre (2015) explains. The ability to borrow from other disciplines and gain an interdisciplinary advantage is an attribute of corpus stylistics.

\section{REFERENCES}

As Good As It Gets (n.d). Retrieved from http://dramatica.com/analysis/as-good-as-it-gets

Biber, D. (2011). Corpus linguistics and the scientific study of literature: Back to the future? Scientific Study of Literature 1(1), 15-23. https://doi.org/10.1075/ssol.1.1.02bib

Bartlett, F.C. (1932). Remembering: A study in experimental and social psychology, Cambridge: Cambridge University Press.

Bockting, I. (1994). Mind style as an interdisciplinary approach to characterisation in Faulkner. Language and Literature, 3(3), 157-174. https://doi.org/10.1177/096394709400300301

Cook, G. W. (1990). A theory of discourse deviation: The application of schema theory to the analysis of literary discourse (Unpublished Doctoral dissertation) University of Leeds, UK.

Culpeper, J. (2001). Language and characterization: People in plays and other texts. Harlow: Longman.

Hoover, D. L. (2016). (2016). Mind-style. In Sotirova, V. (Ed.). The Bloomsbury companion to stylistics (pp.325-340) London: Bloomsbury Publishing.

Emmott, C., Alexander, M., and Marszalek, A. (2014). Schema theory in stylistics. In Michael B. (ed). The Routledge Handbook of stylistics (pp. 268-283). New York: Routledge.

Fowler, R. (1977). Linguistics and the Novel, London: Methuen.

Fowler, R. (1996). Linguistic criticism (2nd ed.). Oxford: Oxford University Press 
Gibbons, A., \& Whiteley, S. (2018). Contemporary stylistics: Language. cognition, interpretation. Edinburgh: Edinburgh University Press.

Jaafar, E. A. (2019). Examining Seamus Heaney's Poem "A Herbal": A corpus stylistic approach. AlUstath Journal for Human and Social Sciences, 58(1), 17-26. Retrieved from http://alustath.uobaghdad.edu.iq/index.php/UJIRCO/article/view/826

Jaafar, E. A. (2017). Corpus stylistic analysis of Thomas Harris' The silence of the lambs. Khazar Journal of Humanities and Social Sciences, 20(1), 25-42. DOI: 10.5782/22232621.2017.20.1.25.

Leech, G. N. \& Short, M. (2007). Style in fiction: A linguistic introduction to English fictional prose. Harlow: Pearson.

Mahlberg, M. (2014). Corpus stylistics. In Michael, B. (Ed.), The Routledge handbook of stylistics (pp. 378-392). Abingdon: Routledge.

Mahlberg, M., \& McIntyre, D. (2011). A case for corpus stylistics: Ian Fleming's Casino Royale. English Text Construction, 4(2), 204-227. https://doi.org/10.1075/etc.4.2.03mah

McIntyre, D, and Archer, D (2010). A corpus-based approach to mind style. Journal of Literary Semantics, 39(2), 167-182. http://dx.doi.org/10.1515/jlse.2010.009

McIntyre, D. (2005, March). Logic, reality and mind style in Alan Bennett's The Lady in the Van. Journal of Literary Semantics 34(1), 21-40 https://doi.org/10.1515/jlse.2005.34.1.21

McIntyre, D. (2015). Towards an integrated corpus stylistics. Topics in Linguistics, 16(1), 59-68. DOI: $10.2478 /$ topling-2015-0011

McVee, M. B., Dunsmore, K., \& Gavelek, J. R. (2005). Schema theory revisited: Review of educational research, 75(4), 531-566. https://doi.org/10.3102/00346543075004531

Montoro, R. (2011). Multimodal realisations of mind style in Enduring Love. In R. Piazza, M. Bednarek, and F. Rossi (Eds.) Telecinematic discourse: Approaches to the Language of films and television series (pp. 69-83) Amsterdam: John Benjamins. https://doi.org/10.1075/pbns.211.06mon

Obsessive-compulsive disorder.(January 2016). Retrieved from https://www.nimh.nih.gov/health/topics/obsessive-compulsive-disorder-ocd/index.shtml

Palmer, A. (2002). The construction of fictional minds. Narrative 10(1), 28-46. https://doi.org/10.1353/nar.2002.0004

Palmer, A. (2004). Fictional minds. Lincoln: University of Nebraska Press.

Rayson, P. (2008). From key words to key semantic domains. International Journal of Corpus Linguistics, 13(4), 519-549. https://doi.org/10.1075/ijcl.13.4.06ray

Semino, E. (1995). Schema theory and the analysis of text worlds in poetry. Language and literature, 4(2), 79-108. https://doi.org/10.1177/096394709500400201

Semino, E. (2007). 'Mind style twenty-five years on', Style, 41(2), 153-73.

Semino, E. (2008). A cognitive stylistic approach to mind style in narrative fiction. In Carter.R. and Stockwell, P. (Eds).The language and literature Reader (pp. 268-277). Abington: Routledge.

Semino, E., \& Short, M. (2004). Corpus stylistics: Speech, writing and thought presentation in a corpus of English writing. London: Routledge. https://doi.org/10.4324/9780203494073

Semino, E. and Culpeper, J. (eds) (2002). Cognitive stylistics: Language and cognition in text analysis. Amsterdam: John Benjamins. https://doi.org/10.1075/lal.1

Stockwell, P. \& Mahlberg, M. (2015). Mind-modelling with corpus stylistics in David Copperfield. Language and Literature, 24(2), 129-147. https://doi.org/10.1177/0963947015576168

Stockwell, P. (2009). Texture: A cognitive aesthetics of reading, Edinburgh: Edinburgh University Press. 
IJoLLT Vol. 2, No. 2 (September 2019

eISSN: 2637-0484

Stockwell, P. (2015). Cognitive stylistics. In Jones, R. H. (Ed.) The Routledge handbook of language and creativity (pp. 218-230). London: Routledge. 